\title{
Treinarte: a educação em saúde para segurança do paciente
}

\author{
Training: health education for patient safety
}

Formación: educación en salud para la seguridad del paciente

Leisson Domingues Pinheiro ${ }^{1 *}$, Dilton Luis Soares de Farias ${ }^{1}$, Ana Carolina Marceliano Nunes ${ }^{1}$, Adhara Belo Marques ${ }^{1}$, Rubervaldo Cruz Sarmento Filho ${ }^{1}$, Wanderson Carvalho Neves ${ }^{1}$, Paulo Ricardo Silva do Nascimento ${ }^{1}$, Paola Alejandra Valenzuela Reyes ${ }^{1}$.

\section{RESUMO}

Objetivo: Relatar os benefícios de orientar, por meio da arte e refletir sobre a contribuição desta estratégia de educação em saúde com foco na segurança do paciente. Relato de Experiência: Este estudo constitui um relato de experiência de caráter descritivo de um Centro integrado de Inclusão e Reabilitação do estado do Pará em relação a execução das práticas organizacionais obrigatórias relacionado a segurança do paciente. A metodologia criou um caminho natural para a avaliação mediadora para maior atenção da equipe para absorção do conteúdo. Considerações Finais: $O$ Treinarte interfere na rotina das pessoas que frequentam o Centro, sejam colaboradores ou usuários do Sistema Único de Saúde, todos são alcançados direta ou indiretamente, pois tal experiência não passa desapercebida.

Palavras chave: Educação, Segurança do paciente, arte.

\begin{abstract}
Objective: To report the benefits of guiding through art and reflecting on the contribution of this health education strategy focused on patient safety. Experience report: This study is a descriptive experience report of an integrated Center for Inclusion and Rehabilitation of the state of Pará regarding the implementation of mandatory organizational practices related to patient safety. The methodology created a natural way for the mediator evaluation for greater attention of the team to absorb the content. Final Considerations: Trainarte interferes in the routine of people who attend the Center, whether collaborators or users of the Unified Health System, all are achieved directly or indirectly, as such experience is not overlooked.
\end{abstract}

Keywords: Education, Patient safety, art.

\section{RESUMEN}

Objetivo: informar los beneficios de guiar a través del arte y reflexionar sobre la contribución de esta estrategia de educación para la salud centrada en la seguridad del paciente. Informe da Experiencia: Este estudio es un informe descriptivo de la experiencia de un Centro integrado para la inclusión y rehabilitación del estado de Pará con respecto a la implementación de prácticas organizativas obligatorias relacionadas con la seguridad del paciente. : La metodología creó una forma natural para la evaluación del mediador para una mayor atención del equipo para absorber el contenido. Consideraciones Finales: Treinarte interfiere en la rutina de las personas que asisten al Centro, ya sean colaboradores o usuarios del Sistema Único de Salud, todo se logra directa o indirectamente, ya que dicha experiencia no se pasa por alto.

Palabras clave: Educación, Seguridad del paciente, art.

${ }^{1}$ Centro Integrado de Inclusão e Reabilitação (CIIR/INDSH), Belém-PA. *E-mail: leisson.ona@bol.com.br 


\section{INTRODUÇÃO}

As organizações de saúde são sistemas complexos que absorvem mudanças ao modelo de atenção à saúde. São mudanças que acontecem lentamente, e carregam consigo o desafio aos profissionais para trabalharem dentro das novas propostas de modelos. Como forma de preparar os profissionais para esse novo cenário que se constrói, faz-se importante os treinamentos e capacitações, partindo do contexto da Educação Permanente, em que se deve valorizar o saber e o fazer dos profissionais que interagem e intervém a partir da reflexão dessas práticas (LAVICH CRP; TERRA MG; MELLO AL, et al., 2017).

Visualiza-se dessa forma, a educação permanente em saúde como sendo uma estratégia fundamental para que aconteçam as transformações no trabalho, no sentido de descobrir e desenvolver competências dos profissionais, primando pela organização do trabalho, aumento da consciência nos profissionais pela sua responsabilidade em seu processo de capacitação (OLIVEIRA FMCSN; FERREIRA EC; RUFINO NA, et al., 2011).

Alguns serviços oferecidos pelo Sistema Único de Saúde, apresenta como insuficiente os setores de formação em atender as necessidades de qualificação profissional e potencializar a valorização educativa do trabalho, como fonte de conhecimento e aprendizagem local. O Ministério da Saúde reafirmou na portaria GM/MS 1996, que a política Nacional de Educação Permanente é uma estratégia educativa para desenvolvimento do SUS (MACHADO JFFP; CARLI AD; KODJAOGLANIANI VL, et al., 2015).

Como estratégia educativa, no campo da saúde, a educação permanente é compreendida enquanto um conceito pedagógico que articula dimensões da gestão, atenção à saúde, formação, desenvolvimento institucional, controle social em saúde e docência (MONTEIRO RB, 2016). É por isso, que o Centro Integrado de Inclusão e Reabilitação(CIIR) reconhece que esse processo de aprendizagem de diferentes profissionais é desafiador por considerar que as pessoas têm diferentes formas de pensar e valores agregados à sua história de vida, que é relevante quando se pretende estabelecer mudanças em suas atitudes ou habilidades (FERREIRA MLSM; BARBOSA PMK, 2012).

A educação permanente parte do aprendizado significativo, em que o aprender e o ensinar deve integrar a prática diária dos profissionais da saúde, que reflete realidades e os modelos de atenção em saúde em que estão inseridos, com intuito de identificar as situações de problemas (STROSCHEM KA; ZOCCHE DAA, 2012).

Aqui, neste Centro Integrado de Inclusão e Reabilitação, preocupa-se com a qualidade e segurança do paciente. Uma vez, que para controlar os números de eventos adversos, torna-se necessário, investir em treinamentos e qualificar a equipe para que possam dar subsídios a realização de uma prática assistencial segura.

Tem-se um estudo, que apresenta o número de evento adverso com danos aos pacientes como sendo elevado, predominantemente erros hospitalares evitáveis. A segurança do paciente apresenta-se como componente indispensáveis para desempenhar o cuidado de qualidade (TAVARES APM; MOURA ECC; AVELINO FVD, et al.,2018).

Na possibilidade de transformação desse cenário, baseou-se essa ação que descrevemos no aporte teórico da educação em saúde, o qual, utilizou-se do teatro como uma ponte entre a arte e os treinamentos para a segurança do paciente. $O$ teatro pode ser considerado um jogo completo que consegue abranger a criatividade e o aprendizado por meio da descontração, elevando o grau de conhecimento do público assistencial (ZAZIMA TJ; CODO CRB; PAES IAD, et al., 2008).

A segurança do paciente tem sido discutida mundialmente nas últimas décadas, tornando-se um fator essencial para melhoria da qualidade dos serviços de saúde. Mesmo sendo clara e urgente a necessidade de discussão sobre o assunto, ainda há uma lacuna de produções sobre o tema (SOUSA P; MENDES W, 2014). 
Nesse sentindo, criou-se o TREINARTE, nome que vem da junção da palavra TREINAR com ARTE, é uma intervenção cênica que tem como objetivo instruir e reforçar os protocolos de segurança do paciente obrigatórios pela ANVISA e Ministério da Saúde. Essa ação está em vigor no Centro Integrado de Inclusão e Reabilitação do Estado do Pará (CIIR/PA) desde abril de 2019, é uma parceria entre o Núcleo de Qualidade e Segurança do Paciente e o setor de Arte e Cultura do Centro. O propósito é conscientizar profissionais da área da saúde e usuários do Sistema Único de Saúde sobre os riscos dos quais podem estar expostos e garantir que ações preventivas sejam tomadas, podendo, assim, diminuir os riscos de incidentes e contaminações no CIIR.

Visando adequar e transformar esse cenário, o presente estudo tem como objetivo relatar a experiência dos benefícios de orientar, por meio da arte e refletir sobre a contribuição desta estratégia de educação em saúde com foco na segurança do paciente.

\section{RELATO DE EXPERIÊNCIA}

Este estudo constitui um relato de experiência de caráter descritivo de um Centro integrado de Inclusão e Reabilitação do estado do Pará em relação a execução das práticas organizacionais obrigatórias relacionado a segurança do paciente. Para realização do presente trabalho, utilizou-se uma revisão de literatura, que consiste no agrupamento de toda literatura existente sobre determinado assunto, sendo que o pensamento dos diversos autores é analisado de maneira crítica em relação a contribuição positiva ou não que tenham ocorrido a um longo período, facilitando o acúmulo de conhecimento.

O Núcleo da qualidade e segurança do paciente realiza reuniões técnicas preeliminares entre os especialistas envolvidos e a equipe do serviço da arte/cultura para discutir qual a maneira mais benéfica de potencializar à ação educativa e entendimento da equipe multiprofissional em relação aos temas de segurança do paciente. Após discussão, são lançados o cronograma de execução das peças teatrais em um dia da semana, manhã e tarde.

Durante o período de organização da peça, os recreadores adquirem conhecimentos e habilidades que o capacitam a desenvolver todo o processo educativo em saúde, abordando aspectos artísticos e pedagógicos para mediar conhecimentos que contribuem para efetivar o entendimento e as ações para segurança do paciente.

As atividades são executadas por (três) recreadores do setor arte/cultura em áreas assistenciais, como por exemplo, ambulatório, centro de especialidade em reabilitação, serviço auxiliar de apoio diagnóstico, centro especialidade odontológico. Os temas abordados foram aplicando conhecimento focado na segurança do paciente, habilidades e valores para o trabalho diário, trabalho em equipe, comunicação eficaz, reconhecer, notificar, analisar e divulgar eventos sentinelas. Após à apresentação, são registrados total de participantes e registros fotográficos

Nesse sentido a própria metodologia do Treinarte criou um caminho natural para a avaliação mediadora para maior atenção da equipe para absorção do conteúdo. A metodologia apresentou uma ferramenta de motivação entre as equipes e incentivo às práticas assistenciais mais seguras.

No primeiro momento a equipe apresentou certas inseguranças em relação a metodologia, não demonstrando atenção necessária ao conteúdo, despertando uma certa desconfiança da seriedade da atividade e seu propósito. Com o passar do tempo e alinhamento da transmissão das informações, o entendimento da equipe começou a ser observados em relação aos colaboradores em adotar boas práticas para segurança do paciente.

O Treinarte vem demonstrando uma ferramenta ponderosa na disseminação do conhecimento e de baixo investimento, garantindo uma ampla e atraente entrega de conhecimento nas áreas assistenciais para o teórico se tornar prático, aumentando a segurança assistenciais dos usuários. 
O acompanhamento e avaliação da experiência permitiram analisar a contribuição do projeto Treinarte no processo de formação e cumprimento dos treinamentos relacionado a segurança do paciente. De modo geral, apresentou como um recurso pedagógico que apresenta mais vantagens do que o método tradicional. $\mathrm{A}$ equipe apresentou um grau de interesse maior aos temas, um nível de interação satisfatório do público e a criatividade que despertou à atenção dos colaboradores.

O caráter inovador da metodologia está em proporcionar experiências artísticas atreladas a conteúdo específicos do Núcleo de Qualidade e Segurança do Paciente, considerando que a prática do TREINARTE, enquanto intervenção cênica, permite uma experiência prazerosa que instiga a reflexão sobre as temáticas relevantes.

O processo de construção destas intervenções cênicas ocorre a partir de indagações práticas: Qual assunto será tratado? Higienização das mãos? Protocolo de Queda? Quais os aspectos de segurança do paciente serão abordados?

E quais as lições que precisam vir à tona de forma clara e objetiva para o público? Respondidas essas perguntas, a segunda etapa é o trabalho de sala de ensaio, onde surgem conversas a respeito do tema em questão e os colaboradores dão vazão à criatividade, acreditando na filosofia do riso, em que tudo é possível de proporcionar por meio do humor.

O professor de teatro atua nesse processo assumindo a função de diretor da encenação enquanto os três recreadores agem como atuantes, todos são profissionais das artes cênicas com experiências no teatro de rua e na arte da palhaçaria, linguagens nas quais se exercitam técnicas de improvisação, sendo essa uma metodologia que necessita de treino constante para aperfeiçoamento.

\section{DISCUSSÃO}

A inovação é bastante rica e abrangente do que conceito de mudanças, renovação ou a reforma. Requer uma ação persistente. A metodologia inovadora cria um caminho característico para maior atenção e encoraja a participação de todos no processo de ensino e aprendizagem (BUSS CS; MACKEDANZ L, 2017).

Para acompanhar as rápidas mudanças, torna-se importante a aquisição de novas capacitações e conhecimento, intensificar a capacidade de indivíduos, empresas, de aprender e transformar este aprendizado em fator de competitividade para os mesmos (LEMOS C, 2008).

Uma forma de fazer educação em saúde, incentivando a diversificação de estratégias para compartilhar conhecimentos e experiências. Pois quando a equipe de saúde discute e aceita a possibilidade de eventos adversos, alcança-se o progresso para uma cultura de segurança (WEGNER W; SILVA SC; KANTORSKI KJC, et al., 2016).

Na região Norte existem diversas iniciativas que atrelam arte, saúde e educação, a exemplo do Núcleo de Artes como Instrumento de Saúde (NARIS), uma iniciativa de coletivos do movimento estudantil de Belém ligados a Faculdade de Medicina da Universidade Federal do Estado do Pará. Sobre a iniciativa o médico e palhaço Vitor Nina explica que esse Núcleo, objetiva o ensino, a transformação e o aprofundamento do conceito de saúde, por meio da utilização da arte como ferramenta educacional. Esse envolvimento da arte com as práticas de saúde, reafirma a importância que trazem quando despertam nas pessoas a sua capacidade de entender e compartilhar o mundo em que vivem (NINA VL, 2013).

Amparado em iniciativas como a do Núcleo de artes como instrumento de saúde (NARIS), a abordagem TREINARTE no CIIR extrapola os processos convencionais de ensino que se limitam a compreender aprendizagem enquanto transmissão de informações. Para tanto, é necessário destacar que ensinar não é somente quando se transferem conhecimento, mas quando se oportuniza a criação de possibilidades para a sua própria produção ou a sua construção do conhecimento (FREIRE P, 2016).

O "saber de experiência", que é o saber que apreendemos ao vivenciar uma experiência, compreendendo que experiência não é apenas um acontecimento, mas sim um acontecimento que se passa consigo, que toca 
sensivelmente o ser que a vivenciou. Por esta razão a prática de intervenções cênicas do TREINARTE vem alcançando resultados satisfatórios que contribuem até mesmo com a Ambiência, Acolhimento e Valorização do Trabalhador dentro do CIIR, princípios da Política Nacional de Humanização (BONDÍA JL, 2002).

Sendo assim, é possível dizer que o improviso é parte da essência do fazer teatral, complementa a respeito do trabalho destes atuantes, afirmando que não se pode desconsiderar o conhecimento e domínio no momento de realizar o improviso teatral. Uma vez que o improviso artístico é o domínio do ofício juntamente com o talento natural (CHACRA S, 2005).

O Treinarte interfere positivamente na rotina das pessoas que frequentam o Centro, sejam colaboradores ou usuários do Sistema Único de Saúde, todos são alcançados direta ou indiretamente, pois tal experiência não passa desapercebida. Sendo assim, é perceptivo a construção de um espaço de ensino-aprendizagem de quem encena e quem assiste tecem juntos possibilidades para edificar saberes e prevenir incidentes na organização.

\section{REFERÊNCIAS}

1. LAVICH CRP, TERRA MG, MELLO AL, et al. Ações de educação permanente dos enfermeiros facilitadores de $m$ núcleo de educação em enfermagem. Revista Gaúcha em Enfermagem:2017;38(1):62261.

2. OLIVEIRA FMCSN, FERREIRA EC, RUFINO NA, et al. Educação permanente e qualidade da assistência à saúde: aprendizagem significativa no trabalho da enfermagem. Colômbia: 2011:11(1):48-65.

3. MACHADO JFFP, CARLI AD, KODJAOGLANIANI VL, et al. Educação permanente no cotidiano da atenção básica no Mato Grosso do Sul. Rio de janeiro: 2015:39:102.

4. MONTEIRO RB. Educação permanente em saúde e as diretrizes curriculares nacionais para educação das relações étnico-raciais e para ensino de história e cultura Afro-Brasileira e Africana. Saúde Sac. São Paulo: 2016;25(3):534.

5. FERREIRA MLSM, BARBOSA PMK. Educação permanente em saúde: uma estratégia para a formação dos agentes comunitários de saúde. Revista Gaúcha de enfermagem. Porto Alegre:2012;33(1):56-65.

6. STROSCHEM KA, ZOCCHE DAA. Educação permanente nos serviços de saúde: um estudo sobre as experiências realizadas no Brasil.Trab. Educ.Saúde:2012;9(3):505-519.

7. TAVARES APM, MOURA ECC, AVELINO FVD, et al. Cultura de segurança do paciente na perspectiva da equipe de enfermagem. Rev Rene.2018; 19:3152.

8. ZAZIMA TJ, CODO CRB, PAES IAD, et al. Orientação em saúde por meio do teatro: relato de experiência. Revista Gaúcha de Enfermagem: 2008;29(1):147.

9. SOUSA P, MENDES W. Conhecendo os ricos na organização de saúde. FIOCRUZ.2014:452.

10. BUSS CS, MACKEDANZ LF. O ensino através de projetos com metodologia ativa de ensino e de aprendizagem. Revista Thema:2017;14(3): 122-131.

11. LEMOS C. Inovação na era do conhecimento. Ciência tecnologia e sociedade:2000;8;159.

12. WEGNER W, SILVA SC, KANTORSKI KJC, et al. Educação para cultura da segurança do paciente: Implicações para a formação profissional. Escola Ana Nery:2016;20(3):1414-8145.

13. NINA VL. Uma garrafada de arte e ciência: o núcleo de artes como instrumento de saúde, a trupe da procura e suas experiências na interface entre cultura e saúde em Belém do Pará. Trabalho de Conclusão de Curso apresentado para obtenção do grau em Medicina pela Universidade Federal do Pará. 2013.

14. FREIRE P. Pedagogia da autonomia: saberes necessários à prática educativo / Paulo Freire 54르 ed - Rio de Janeiro: Paz e Terra, 2016.

15. BONDÍA JL. Notas sobre a experiência e o saber de experiência. Universidade de Barcelona, Espanha. Tradução de João Wanderley Geraldi Universidade Estadual de Campinas, Departamento de Linguística, 2002.

16. CHACRA S. Natureza e sentido da improvisação teatral. 1 ed. São Paulo: Perspectiva. 2005. 